\title{
À qui appartenait le pavillon de parlementaire du 14 septembre 1759
}

\section{Lucien Brault}

Volume 10, numéro 1, juin 1956

URI : https://id.erudit.org/iderudit/301747ar

DOI : https://doi.org/10.7202/301747ar

Aller au sommaire du numéro

\section{Éditeur(s)}

Institut d'histoire de l'Amérique française

\section{ISSN}

0035-2357 (imprimé)

1492-1383 (numérique)

Découvrir la revue

\section{Citer cet article}

Brault, L. (1956). À qui appartenait le pavillon de parlementaire du 14 septembre 1759. Revue d'histoire de l'Amérique française, 10(1), 115-116. https://doi.org/10.7202/301747ar d'utilisation que vous pouvez consulter en ligne. 


\title{
A QUI APPARTENAIT LE PAVILLON DE PARLEMENTAIRE
}

\author{
DU 14 SEPTEMBRE 1759
}

C'est là une question de minime détail qui n'intéresse pas beaucoup la grande histoire, mais qui peut avoir son intérêt pour quelques historiens et qui comporte beaucoup d'importance pour les généalogistes à la recherche de faits particuliers pour faire ressortir le rôle joué par les individus.

On sait qu'après la bataille des Plaines d'Abraham, qui eut lieu le 13 septembre 1759, l'armée anglaise s'occupa de consolider sa position et d'enterrer les morts. Pendant ce temps, la garnison francaise, dans l'enceinte de la ville de Québec, essayait, autant qu'elle le pouvait, d'enrayer tout progrès ennemi, en tirant sur lui des fortifications. Entre les murs de Québec et le camp anglais, ce que l'on appellerait aujourd'hui le «no man's land», il se trouvait des soldats français tués au combat de la veille, que l'on n'avait pas eu le temps d'enterrer.

Dans l'après-midi du 14 , Lusignan, ${ }^{1}$ major en second, au régiment de Languedoc, reçut l'ordre d'aller enterrer ces morts sur la ligne de feu, les Anglais ne les ayant pas inhumés.

Pour se rendre au camp anglais et obtenir temporairement une suspension du feu, Lusignan utilisa un drap blanc en guise de pavillon de parlementaire. C'est ici que se pose notre question initiale: A qui appartenait ce pavillon ?

Un document de la série du «Secrétaire du Gouverneur $(\ll S »)$, vol. 2, document $6^{\text {e}}$, conservée aux Archives publiques du Canada, nous en donne la réponse. En effet, on y trouve l'extrait suivant:

«Je Veuve de françois Girard citoyen de québec déclare avoir Entre mes mains Les papiers de Canada dont la Teneur suit cy dessous, Lesquels m'appartiennent. Scavoir,

1 Louis-Antoine Lusignan était le fils aîné de Paul-Louis (1691) et de Madeleine-Marguerite Bouat. Il naquit le 21 septembre 1726, entra dans les troupes de la marine et servit au moins de 1747 jusqu'à la prise de Québec, moment où il dut mettre bas les armes. 
Copie d'un Certificat signée Lusignan,

\section{Artillerie.}

Je Soussigné, certifie quela femme de françois Girard citoyen de cette ville a fourni un drap blanc pour faire un pavillon de parlementaire, En foy dequoy, J'ay signé le présent pour qu'il luy soit rendu par le Roy. àquébec le $16^{\mathrm{e}} 7^{\text {bre }} 1759$

Signé

$$
\text { Lusignan. 》 }
$$

La date du 16 septembre nous dit que la mission de Lusignan fut terminée à ce jour et qu'il avait signé la note de paiement pour le roi.

Les généalogistes pourraient noter cet autre renseignement que la réquisition du drap est faite à la femme de François Girard le 16 septembre 1759 et que le bordereau de papier monnaie est signé de la «veuve Girard », le 17 mars 1764. Ce qui veut dire que François est décédé entre ces deux dates.

\section{Lucien BRAULT}

Archives publiques du Canada. 